\title{
Knowledge constructions in research communities: The example of agri-rural researchers in Denmark
}

\author{
Lene Møller Madsen $^{\mathrm{a}, *}$, Hanne Kirstine Adriansen ${ }^{\mathrm{b}}$ \\ ${ }^{a}$ Centre for Science Education, University of Copenhagen, Universitetsparken 5, DK-2100 Copenhagen Ø, Denmark \\ ${ }^{\mathrm{b}}$ Danish Institute for International Studies, Strandgade 56, DK-1401 Copenhagen K, Denmark
}

\begin{abstract}
Construction of scientific knowledge can be seen as a struggle over who should define the terms and conditions of legitimate fields of research. Sociologists of scientific knowledge (SSK) have pointed to the importance of analysing scientific knowledge in the same way as other types of knowledge. This idea guides the present paper on Danish research in agriculture and rural areas. Based on an ethnographic study of researchers involved in rural studies, we take stock of the agri-rural research community in Denmark and reflect upon the how and why 'fashions' in Danish rural studies differ from 'fashions' in rural studies in the UK. In the analysis, we show how a research community construct and reconstruct itself in relation to what is perceived as legitimate fields of research. Finally, the paper gives insight into the research world of those doing research outside the UK and adds to the discussion of 'putting philosophies of geography into practice' that is on-going in British geography.
\end{abstract}

(C) 2006 Elsevier Ltd. All rights reserved.

\section{Introduction}

Based on the idea within sociology of scientific knowledge (SSK) that science studies should be cultural studies (Demeritt, 1996), this paper discusses the construction of scientific knowledge among agri-rural researchers in Denmark. The purpose of the paper is to take stock of the current state of agri-rural research in Denmark; and without having a comparative scope, we relate 'fashions' in research in Denmark to current trends in British research. We use it as an example of how a research community is constructed and reconstruct itself through a struggle over what is perceived legitimate fields of research. In this way, we also give insights into the research world of those doing geography outside British rural geography. It is a report from the periphery of the dominating AngloAmerican geographical writing space - to use the centreperiphery illustration described by Simonsen (2004). We use an ethnographic approach and thereby, we highlight the context of the individual in her/his research practice

\footnotetext{
*Corresponding author. Tel.: + 4535320459 .

E-mail addresses: 1mmadsen@cnd.ku.dk (L.M. Madsen), hka@diis.dk (H.K. Adriansen).
}

and use a disciplinary reflexivity whereby scientific methods are used to scrutinize the making of research (Lorimer and Spedding, 2002b). Inspired by this, the present study's empirical basis is qualitative interviews, participatory observations, telephone questionnaires, and our own more than 10 years knowledge and experience as members of the agri-rural research community in Denmark.

The paper is organised in five sections. In the first section, the methodological approach is outlined. This consists of a definition of the research community and an elaboration of the data collection. The second section is the analysis. This consists of six subsections; after characterising the research community, we present the traditions of thought and research activities found in the agri-rural research community in Denmark in the sections: topics of research, identities and belonging of the researchers, methodologies reproduced through teaching, their used methods and philosophy of science, and finally networking and canons. In the third section, we discuss conditions for conducting agri-rural research in Denmark. The discussion is based on the analysis in the previous section combined with an analysis of structural issues such as institutional setting and funding mechanisms. Different 'fashions' in rural research in Denmark and the UK and what might be 
learned from the periphery of Anglo-American geography are discussed in the fourth section. Finally in the fifth section a conclusion is given.

\section{Methodological approach}

The scientific fascination with ethnographic methods and the call for studies of the researchers themselves have been stimulated by different disciplines. One is the work within SSK that focuses on how social factors influences the production of science on a micro-level e.g. studies of the production of science in laboratories (Knorr-Cetina, 1981; Latour and Woolgar, 1986). These thoughts were developed in the mid-1970s as a response to Kuhn and his 'revolutionary' view of science (Kuhn, 1962). KnorrCetina, Latour, and Woolgar further developed these thoughts in interplay with other researchers in the 1980s and they can be placed in the philosophical context of what can be labelled social constructivism (Wenneberg, 2002). The present study draws upon the philosophical and methodological thoughts from SSK.

\subsection{Defining the research community}

With regard to research and publication, Johnston (2003, p. 133) has noted that 'UK geography cannot be presented as a single academic community with strong internal ties, but rather as a conglomerate of separate communities writing for different audiences'. Based on the idea that a discipline can consist of several academic or research communities, our 'unit of analysis' is a particular research community in Denmark.

Some studies of 'fashions' within disciplines or research communities have solely relied on analysis of scientific papers (see e.g. Johnston (2003) on geography, and Morris and Evans (2004) on agricultural geography). Instead of analysing scientific papers, we analyse the research community by locating research thinking, activities, and representation in its spatial setting. We have chosen this approach in order to benefit from our knowledge as insiders and in combination with qualitative interviews to outline a picture of the tacit rules and codes of conduct as well as the hegemonic discourses in the research community. This picture could not have been outlined only by analysing the research products such as scientific papers. The approach is inspired by Livingstone (2000), who among other historians of geography, has argued that the development of the discipline should be understood in the context of space and place. Following this, and in line with Simandan (2002), we understand the researcher as challenged through his/her daily research and teaching practice constantly reworking and reshaping the tradition of thoughts at the specific research place. ${ }^{1}$

\footnotetext{
${ }^{1}$ Hence, the present paper can be seen as a contribution to the discussion of 'putting philosophies of geographies into practice' that was raised at the 2002 annual meeting of Royal Geographical Society - Institute of British
}

Subsequently, we find that within each research community, there are 'fields of legitimate research'; these are the shared meanings, negotiations, and beliefs that legitimate certain research practices and lead to the abandonment of others. We use the concept community similarly to Liepins (2000a, b) who establishes a conceptual framework for an analysis of communities. ${ }^{2}$ She states that exploring meanings, identifying practices, and mapping spaces and structures of the community allows for considerations of the ways in which communities are constructed. In the present context, this applies to the individual researcher as well as to the research community as a whole. Furthermore, a research community can be seen as an 'intellectual space' as it has been described by Livingstone: 'when we try to understand someone's behaviour it is imperative that we take into account the settings which render their actions and expressions intelligible both to themselves and to others' (2000, p. 5). Hence, a research community is an intellectual space inhabited by a set of ideas. This means that within this space justification of e.g. research designs is not 'necessary' because all the members share the same ideas about 'valid research'. Another implication is that it is difficult for outsiders to enter the research community unless they share the same intellectual ideas. In this way, research can be perceived as a struggle over right and wrong research and like Sidaway $(1997,2000)$ we use the empirical material to reflect upon academic fields of power.

To sum up, research communities usually extend beyond one academic institution and can be characterised by the fact that researchers participate in meetings, seminars, etc. with other institutions that are part of the community. In case of institutions having an educational component, members of the research community are used as external examiners, they attend Ph.D. defences given by other members of the community, etc. This has been described by Bensel (2003): "when we train doctoral students and later review them for promotion and tenure, we are asked to do so as members of a discipline, an "imagined community" ... of scholars who share a common orientation towards what is considered knowledgeably informed and skilfully applied work' (2003, p. 106). Finally, it should be noted that sometimes the relation extends beyond collegial community and members of a research community become friends.

\footnotetext{
(footnote continued)

Geographers. Here one session was devoted to addressing "the relationships between the everyday activities of geographers and the theoreticalmethodological tools that we choose to employ in our research and our teaching. Contributors were invited to consider aspects of disciplinary practice that tend to be portrayed as mundane or localized but represent the very routines of what we do' (Lorimer and Spedding, 2002a, p. 227 emphasis in original).

${ }^{2}$ It should be noted that Liepins (2000a, p. 23) uses the concept community with quotation marks to indicate the constructed and contestable nature of the concept.
} 


\subsection{Data collection}

We had a clear idea about the limits of the agri-rural research community, even though in some cases it was difficult to define 'insiders' and 'outsiders'. One defining element was that all members of the research community should know each other and have some kind of working relation, e.g. Ph.D.-supervisor relationship, being in the same research programme. Further, all members of the research community should be actively involved in 'reproduction of the research community' through teaching. Although dominated by geographers, we found that researchers outside geography departments were part of the agri-rural research community. It is acknowledged that this categorisation is inevitably subjective, the product of a particular 'reading' of who was included in the agri-rural research community.

The agri-rural research community consisted of 15 people. They were employed at three different universities. In order not to 'confuse' the researchers outside geography departments, we decided to label the research field 'rural studies' during interviews. We deliberately used the English term because rural studies is a broad category without a disciplinary rooting, yet encompassing the research carried out by these people. Thereby we use the term 'rural studies' differently from how it is used among researchers in the UK. Rural studies is carried out at an additional five institutions. For a total list of Danish universities and research institutions were researchers carry out rural studies see Table 1. A number of researchers at these research institutions have some kind of contact with the agri-rural community. However, due to the lack of teaching activity and regular research contact with the community they have been excluded from the analysis.

All the 15 members of the agri-rural research community were included either in the qualitative interviews or telephone questionnaires. Hence, the empirical material consists of five qualitative interviews, ten telephone questionnaires, and 10 years of participatory observations in the research community. ${ }^{3}$

The five qualitative interviews were conducted in June and July 2003: Two interviews with professors and three interviews with younger members of the research community placed at two different universities. ${ }^{4}$ All interviews were taped in agreement with the interviewees and later transcribed. The interviews were conducted in the inter-

\footnotetext{
${ }^{3}$ Due to the small size of the community and our own position within it, it has been necessary with careful considerations of how to both secure anonymity and be able to present the results to a wider audience. In order to avoid delicate situations and secure openness towards the questions and the project in general, we have therefore decided firstly to present the analysis of the statistical information in general terms and not divide it into small groups which could easily be recognised, and secondly only to use citations which cannot easily be traced back to the interviewee. The code given at the end of each citation is for data validation purpose only.

${ }^{4}$ These were Institute of Geography (University of Copenhagen) and Forest and Landscape (The Royal Veterinary and Agricultural University).
}

Table 1

Danish universities and institutions where researchers carry out rural studies

- University of Copenhagen - Institute of Geography

- The Royal Veterinary and Agricultural University-Forest and Landscape, Department of Economics and Natural Resource Management

- Roskilde University - Department of Geography and International Development Studies

- Aalborg University - Department of Development and Planning

- University of Southern Denmark - Institute of History and Civilisation

- The Danish Centre for Rural Research and Development - ass. with the University of Southern Denmark

- Ministry of Environment-National Environmental Research Institute

- Ministry of Food, Agriculture and Fisheries - Danish Institute of Agricultural Sciences

viewee's office if possible. The office location was preferred in order to use the spatial aspect strategically to situate the interview in its social and cultural context and thereby enrich the explanations of the participants as described by Elwood and Martin (2000).

We explained the content of the interview by referring to a workshop facilitated by the Danish anthropologist Kirsten Hastrup taking stock of anthropology in Denmark. Here Hastrup asked the participants to, for instance, name the ten 'greatest hits' among anthropological literature. We used this as inspiration for making the questions, which guided each interview. In addition to questions meant for assessing the state of rural studies, our questions referred to the daily activities of the researcher and the structure of and relations within the research field of rural studies (e.g. the existing personal and professional networks, conference attendance, teaching, interactions with the field, institutional framework, political climate, and funding programmes). We see these issues as constantly constructing and reconstructing the "boundaries for research' within the research community and therefore important to include in the analysis. Further, this approach means that we build our understanding of the research field on how individual actors respond differently to structures (see also Madsen and Adriansen, 2004). A few questions referred to the interviewees' biography. One question related to the 'history of a publication'. In line with Kitchin and Fuller's call for transparency in publishing and presenting geographical knowledge, we asked the interviewees to outline how a paper or chapter had evolved from the author's first idea, over the influence of peers and networks, to the end-product (Kitchin and Fuller, 2003). The content of the questions was further inspired by the geographer Simandan (2002, p. 285) who argues that: 'what is meant by a good geographer is always placespecific'. Following this, we asked questions that were meant to disclose what the interviewees considered 'proper rural studies', e.g. we asked what students ought to be acquainted with during their undergraduate studies, etc. 
Hence, research is seen as an ongoing individual and collective performance linked to the actual place $^{5}$ where research occurs. The interviews were made in to order capture both the production and reproduction ${ }^{6}$ of the legitimate fields of research within the research community. In this paper, individual rural researchers are therefore viewed as part of a research community each responding through their ways of doing research to the negotiated, contextual, contingent, and adaptive nature of research. Research is seen as a fundamentally negotiated process that is translated and transformed by the researchers throughout the process, as described by Bradshaw (2001).

In order to substantiate the information from the qualitative interviews, telephone questionnaires where made with agri-rural researchers in 2004. Telephone questionnaires provided much more information than could be obtained from statistics and were further preferred due to the lack of statistical material about the community ${ }^{7}$ and poorly updated institutional homepages. The telephone questionnaires were made with researchers at three universities. ${ }^{8}$ In total ten telephone interviews with eight associate professors, one post doc, and one Ph.D.student. Thirty-eight questions were prompted within the six categories: education, employment, research, finance, network and personal data.

The last source of information was participatory observations. We are both human geographers educated from Institute of Geography, University of Copenhagen. During our post graduate studies, we were included in the agri-rural research community. In this context, it is worth noticing that while one of us has changed research community, the other is still an active member of the research community, teaching, networking, and applying for funding with other members of the community. Hence, we are positioned in the very field we are trying to describe and in this way we are part of the discourse we analyse. The methodology is similar to Ehn and Löfgren's study of behaviour in Swedish academia (Ehn and Löfgren, 2004). Their study is ethnographic, based on many years active participatory observations of large and small details and habits in the environment, conversations and interviews

\footnotetext{
${ }^{5}$ Here place is in the notion of both the physical and social place. As Sidaway (1997) notes, academic work often crosses conventional boundaries of place such as for example office-home.

${ }^{6} \mathrm{By}$ 'reproduction' we mean the transfer of research practices and knowledge to students.

${ }^{7}$ Ståhle (2004) made an investigation of the development in research employment at universities in Denmark 1998-2003. Unfortunately, it is only made to the level of faculties and can therefore not be related to the agri-rural research community. However, we find that the report is valuable as indicator of tendencies in the Danish research society and have included some of his results in our discussions of researchers' mobility, employment, etc.

${ }^{8}$ Institute of Geography (University of Copenhagen), Forest and Landscape (The Royal Veterinary and Agricultural University), and Department of Geography and International Development Studies (Roskilde University).
}

with members of academia. ${ }^{9}$ This type of study can be characterised as a micro-level analysis where researchers speak within, rather than across, worlds (Browne, 2003).

\section{The agri-rural research community in Denmark}

In this section, the agri-rural research community in Denmark is analysed. First we present a characteristic of the community including its 15 members; then follows an analysis of their research activities. The issues presented are selected in an attempt to capture the complex and negotiated tradition of thoughts and research activities observed among Danish agri-rural researchers. The material has been organised in six subsections although we acknowledge that they are highly interwoven and not easily separated. ${ }^{10}$

\subsection{Characteristics of the research community}

For a number of reasons, the size and importance of geography as a discipline is much smaller in Denmark than in the UK and some sub-fields are less manifest or not existing. There is no verbalised distinction between rural and agricultural geography, for instance; instead it exists as one sub-field. In content, it does not simply equal either the field of agricultural geography or that of rural geography as they are outlined in The Dictionary of Human Geography (Whatmore, 2000; Cloke, 2000). It includes parts of both agricultural geography and rural geography but also what could be labelled land-use studies.

The research community is very homogeneous. Among the 15 researchers, seven are women and eight are men. Their age ranges from 32 to 58 years with an average age of 45. There is no gender difference as the women were in average 44.4 years old and the men 45.5 years old. In relation to the Danish research society in general, the numbers show a concentration of researchers between 40 and 49 years ( 6 out of 15 compared to $26 \%$ in general) and subsequently no researchers under 29 years and over 60 years compared to $2 \%$ and $18 \%$ for the society in general (Ståhle, 2004). In terms of disciplinary background, there is a bias towards geography as eight of the researchers are geographers. Two have a background in agronomy, two in landscape architecture, one in horticulture, and finally there is one biologist and one architect.

Also in terms of academic position, the community is very homogeneous although with a slight domination of men in the higher positions. There are three professors, one female and two males, eight associate professors, three

\footnotetext{
${ }^{9}$ In their book: Hur bliver man klok pa universitetet? (How to become wise at university?) they describe the academic practices such as writing and teaching and combine it with anecdotes from academic life and researcher biographies in order to provide a comprehensive understanding of the tacit rules and codes of conduct in academia and the researchers' ambivalent feelings in this environment (Ehn and Löfgren, 2004).

${ }^{10}$ It should be noted that the interviews were conducted in Danish. We have chosen verbatim translation over 'elegant' ones.
} 
females and five males, two post doc/assistant professors, both females, and two Ph.D.-students, one female and one male. In Danish academia as a whole, women constitute 24\% (Ståhle, 2004). Hence, the agri-rural research community has an 'over representation' of women. When comparing with Ståhle's analysis of Danish academia, it is seen that the agri-rural research community also has an over representation of professors at 'the expense' of assistant professors - in Danish academia 16\% are professors and $24 \%$ assistant professors.

\subsection{Topics of research}

The research interests of the agri-rural researchers cover quite a wide range of issues from landscape management and planning, agricultural systems, and land use to evaluation of EU policies, environmental impact, and geographical mapping but the study of landscape is the focus of their research. It is within this topic they take departure; in various ways they study landscape changes and planning, and farmers' behaviour and attitudes in relation to landscape.

The interviewees perceive rural studies as a research field overarching many disciplines. It ranges from anthropological, sociological approaches to economic ones. In this context, the study of landscape is seen as a theme connecting these different approaches. All of the approaches are seen as indispensable in order to understand the landscape and its changes. However, together with an awareness of a necessity to include all the different approaches, the interviewees were very conscious that they themselves only did research within a small area of this research field - namely in relation to land use and landscape changes:

I think that rural studies in Denmark consists of circles $[\ldots]$ and one of the more pronounced of these circles is the one relating to landscapes (E 10-27-29). ${ }^{3}$

During the interviews, it became clear that the focus on land use and landscape changes often is interwoven and not easily separated from the study of agricultural practice and agricultural development. The interviewees argued that the key to understand landscape changes is to understand the agricultural use of the landscape while acknowledging that other factors also are important. This is closely related to a belief in a strong link between landscape changes and agricultural development. The link is also evident in many of the interviewees' academic papers.

According to the interviewees, rural studies are not territorially delimited to Denmark and other 'Western' countries. Although all the interviewees made research in rural Denmark (and one also in rural Africa), they all considered developing countries within the research agenda of rural studies. Some mentioned this without us asking about it. Nevertheless, few had research relations with colleagues working in developing countries and none included these colleagues in their research network on rural studies although these might sit in the office next door. One of the interviewees had previously worked with implementation of development projects in Africa, but as a researcher today he/she works with Denmark. When asked if he/she cooperated with colleagues working in developing countries, he/she noted:

... not in my research, but in my teaching and I still identify with many of those working in developing countries (A 10-127-128).

Consequently, research of rural areas in developing countries is included in the category 'rural studies'.

As mentioned above, the research field of the Danish agri-rural research community include aspects from both agricultural and rural geography in the British understanding of these subjects. However, aspects such as postmodern and post-structural understandings of society-space, nature-society, and self-other are not studied by the researchers in this community. Generally, the rural is not studied as a socially constructed place but instead as a physical place.

\subsection{Identities and belonging of rural researchers}

We have studied the construction of identities and belonging at two levels - the community level and the institutional level. When we told the interviewees who were included in the study, they all agreed that these researchers belonged to the same community. The labelling of this community was a problem, however. As mentioned, we chose to use the English term rural studies because this is a broad category encompassing a variety of disciplines. Nevertheless, it turned out that rural studies was not a familiar concept for Danish agri-rural researchers, especially not for the 'older' members of the research community. Further, some of the interviewees did not find rural studies an appropriate label for their research:

I don't call what I'm doing rural studies myself, I call it something else, I call it landscape management... landscape policy, I have started calling it (E 1-3).

I have never used the word myself and I don't think I'd use it about any of the things I would do... but of course I'd also think that a lot of what we are doing is studies of rural areas (D 1-5).

Despite the concerns about labelling their research rural studies, the interviewees acknowledged the existence of a Danish research community engaged with 'rural matters' and they all felt they were a part of the agri-rural research community.

The interviewees' institutional identity was touched upon in several ways, for instance when they told about their carrier path - both the one already taken and their plans and expectations for the future. All the five interviewees remained at the institution where they had been admitted for their undergraduate studies. While they 
had had 'detours' to other academic environments, or even outside academia, these were minor detours and the researchers did not articulate any wish to be employed elsewhere. This was not necessarily out of pride of their institution; it rather reflects the low mobility of Danish researchers. ${ }^{11}$

At first sight, the telephone questionnaires showed a different tendency. Four of the ten questionnaire interviewees were employed at the institution where they had been admitted for their undergraduate studies. Three of these had had short-term detours both inside and outside academia - mostly in their beginning of their careers. Six of the questionnaire interviewees were employed at another institution from which they had graduated. Three of these had remained at the institution where they got their first employment. Of the remaining three, one had previously been employed outside academia and two had been employed at other research institutions.

Although these numbers indicate that the researchers in the agri-rural research community are mobile, the flow the last 10 years has predominantly been to other institutions within the community thereby reproducing the ideals and ways of thinking within the community. This is not different from the Danish research society as a whole. Here $74 \%$ of new employees in 2001-2003 were recruited internally, i.e. from the department that announces a new position and this number has increased from 1998 to 2003, hence researchers in Denmark have become less mobile. Further, less than $10 \%$ of the new employees came from another university (Ståhle, 2004).

\subsection{Methodologies reproduced through teaching}

One way of understanding the fields of legitimate research is to look at the issues and methods that are found important to teach students. The interviewees emphasised a wide range of different subjects that were important for the students to be acquainted with in order to give them an understanding of "what is going on in rural areas'. This is combined with a wish to train students in different methods enabling them to do rural studies: statistics, mapping, questionnaires, and interviewing. The interviewees highlighted the students' ability to understand how the different topics manifest themselves in physical structures within the landscape. Hence, an interdisciplinary approach is valued highly.

The interdisciplinary approach is combined with a belief in learning by working with a distinct study area. The interviewees all took point of departure in empirical 'evidence' in order to establish a framework of explanatory

\footnotetext{
${ }^{11}$ It is beyond the scope of this paper to compare the low frequency of movements between the universities in Denmark with university mobility in Anglo-America. It suffices to notice that researchers' low mobility is not only due to local embeddedness and involvement in the local society, because mobility between universities within the same city is low.
}

power for their research-as described by two of the interviewees:

Simply take an area... take a distinct area, take it and say in that area we need to know something about the economic relations, how the cultural traditions are in the area... how the general historical development in the area has been, how has the landscape developed, how is... demographics in this area in order to get this whole field of rural areas covered (C 2-7-13).

If we do not have something empirical in common, then it will never become interdisciplinary (E 9-16-17).

Based on an acknowledgement of the necessity of a combined interdisciplinary and empirical approach, the individual researcher is allowed to focus on a specific topic within the research field. In this way, a research focus on the link between agriculture and landscape changes is legitimized and can be understood.

\subsection{Used methods and philosophy of science}

Due to our interest in the sociology of scientific knowledge, we wanted to uncover the interviewees' approach towards philosophy of science and discussions of methodology and research design.

As mentioned, the interviewees' ideal of research was to include as many aspects as possible in the understanding of the landscape and its changes. However, this was not linked with discussions of the philosophical and methodological implications of integrating different disciplines that are grounded in both human, social, and natural sciences. During the interviews, it was seen both by the reactions of the interviewees towards discussing philosophy of science and in their direct answers to these questions. This may be due to the interviewees' professional background within a natural-science based environment ${ }^{12}$ where such concerns are not perceived as relevant. When asked how he/she would position him/herself in terms of philosophical point of departure and about the implications of this for his/her research, one of the interviewees replied:

Well, I don't know. It does not mean that much to me in my daily work ... but, well, I find it interesting that there has been different periods and ways to approach the world, but it is not important to me in my daily work (B 8-3-9).

As noted above, all of the interviewees were focused on empirically based research and a hesitation towards other types of research could be found:

If we move in a direction that does not appreciate thewhat should we label it - concrete empirical documentation, well then I have some problems with that (D 8-5-7).

\footnotetext{
${ }^{12}$ What we have defined the agri-rural research community in Denmark is based on researchers located at institutions under natural science faculties or environments.
} 
These positivist and empirical approaches were constantly negotiated through the interviews, which in turn lead to an emphasis on in-depth empirical studies and to little interest in the philosophy of science. This is also evident in many of the interviewees' academic papers, which have very few reflections over philosophy of science. They can all be characterised as based on an implicit positivist way of doing research.

The influence of the natural science setting was clear when discussing the perception of scientific research among members of the research community. Especially younger members of the community felt they could only legitimise their research as 'scientific' if it was conducted within a natural science setting:

What is right, what is real scientific research? ... when we have to do it really scientific then it has to do with numbers and some kind of GIS and stuff, cause that's when it becomes real, that's when it is real science... it has to do with what is scientific research and then it is predominantly natural science (C 10-65-70).

For others these issues were not spoken of, which indicate assimilation of the existing codes of conduct within the research environment-like an implicit voice within the community. These researchers are thereby reproducing the boundaries of research without questioning them.

The lack of discussions of philosophies of science made it difficult to oppose to the existing boundaries of research even though some researchers - especially the younger ones-did not find them legitimate. As one of the interviewees said:

You have to play against something that is really not there and ...it is difficult to situate oneself so to speak, because you can only situate yourself in relation to what you don't want to be.... In some ways you could say that's what I'd like to do in the future, to get the philosophy of science included (C 10-72-75).

Based on our own experiences within the research community, it can be argued that researchers are 'brought up' with a natural science ideal for conducting research. Although some of the interviewees had challenged this ideal in terms of methods, it still affected the issues addressed by the researchers. Moreover, during our more than 10 years within the research community we have rarely come across discussions of philosophy of science.

In the telephone questionnaires, people were asked to categorise their research as predominantly empirical, methodological or theoretical. Six of them answered empirical, one theoretical, two a combination of empirical and methodological, and one found that his/her research was a combination of all three. These data confirm us in our observation of the community as very much founded on an empirical research approach. To be empirically oriented does not imply mean a neglect of philosophical issues. However, we found that the interviewees were more like miners than travellers to use Kvale's (1996) metaphor. For a miner, empirical work is meant to 'unearth the valuable metal' of the ground. The miner sees empirical knowledge as buried metal waiting to be uncovered, uncontaminated by the miner. The traveller, on the other hand, sees empirical work as a journey that leads to a tale to be told upon returning home. The miner metaphor pictures a common understanding in modern social sciences of knowledge as 'given' whereas the traveller metaphor refers to a post-modern constructionist understanding (Kvale, 1996, p. 5).

\subsection{Networking and canons}

Another aspect of identifying oneself as an agri-rural researcher is the establishment and use of a research network as well as the recognition of a 'canon' of rural literature. We wanted to know if such networks existed and how the interviewees used them. It should be noted that we did not specify whether we were talking about formal or informal networks. It turned out that the interviewees had quite different notions of this:

...there is no such network and that is a great problem in Denmark [that there is no network]. And there is noone who works actively towards establishing one and that is an even larger problem (E 6-10-12).

Absolutely [there exists a network]. Networks can be more or less formally based and defined. It is a kind of floating organic structure, which suddenly-so to speak - crystallizes. Then a project group appears or a commission on something is appointed or a centre structure is made on basis of different elements. So it is a combination of something very independent and indefinable and so all of a sudden there is a specific reason for it to be made (A 6-17-26).

I think there are networks, which overlap a little. I think it is very like...hopefully they do overlap a little. But, but the big chromium-plated network does not exist (C 10-441-447).

In the telephone questionnaires, eight persons indicated that they participated in rural networks. In these interviews, the issue of funding in relation to networks was in focus. Nine of the interviewees indicated that there is a strong link between being member of a network and secure funding for research. ${ }^{13}$ As indicated by one researcher: 'In order to be included in an application, in particular a large EU programme, it is important to be member of a network' and another researcher said: 'Often networks are established because people want to apply for funding together'.

Another important aspect of networking is conference attendances and personal contacts with researchers in other countries. Many of the interviewees did have links to

\footnotetext{
${ }^{13}$ Only one did not question this relation. He/she did just not find that his/her current research had the link.
} 
international research communities, for instance through EU-funding, although this contact was usually not related to specific agri-rural communities. Despite these links to international researchers, the interviewees did not express a strong sense of belonging to an international community.

In order to uncover if the interviewees had a canon, they were asked which papers they would select for a publication showing the highlights of rural studies in Denmark. This appeared to be quite a difficult question to answer. The interviewees did not refer to an existing body of literature, i.e. there is no Danish canon. Likewise, the interviewees' suggestions of important literature within rural studies internationally did not overlap neither in titles nor in authors. Among the authors mentioned, only one was mentioned by all the five interviewees. Thus, the researchers did not find an intellectual relationship through a common acknowledgement of the major works within rural studies. In that respect the community is linked together by the empirical research agenda rather than by a theoretical canon.

\section{The conditions for conducting agri-rural research in Denmark}

In order to understand the construction of knowledge within a research community, it is necessary to analyse the conditions for conducting research. Hence, in this section, the conditions for conducting agri-rural research are discussed. By conditions we mean both external structures such as institutional settings and funding mechanisms and internal mechanisms such as the tacit rules and ideals that exist within the research community and guides the type of research made.

These issues are obviously interrelated. Research ideals within the agri-rural research community are produced and reproduced both by individual researchers and by the research community as a whole. Both the institutional settings and funding mechanisms are structures that ensure a constant reproduction of the existing way of thinking within Danish academia.

\subsection{Research ideals within the agri-rural research community}

Among the researchers, who belong to the Danish agrirural research community, a number of research ideals of 'proper agri-rural research' can be found. These ideals are not hegemonic, but they are part of the constitution of the boundaries of research. These ideals are important because 'claims to knowledge are claims to power' (Demeritt, 1996, p. 485). Hence, we agree with Demeritt's idea that discussions of research, objectivity, and scientific facts are discussions over what is considered 'real knowledge' and whose voice will be heard in the fight to define it.

The research ideals found in the research community are part and parcel of the institutional setting within natural science. This can be seen as there is a strong bias towards a positivist ideal for conducting research. This was reflected both in the answers per se and in the ways of answering - a hesitation towards questions concerning philosophy of science for instance. Also the interviewees subscribed to a discourse where fieldwork provides researchers with 'evidence' that need not be questioned.

Two major research ideals have been identified. These are interwoven and underlie what we have termed 'fields of legitimate research'. We have named the two ideals 'the holistic research ideal' and 'the empirical research ideal'.

\subsubsection{The holistic research ideal}

Rural studies is perceived by the Danish agri-rural researchers to be a very broad category including a number of ways to understand and analyse the rural in general and landscapes/land use in particular. The interviewees all emphasised that they could only contribute with one part of the analysis and therefore they encouraged interdisciplinary ${ }^{14}$ studies of rural areas. While the interviewees had different disciplinary background and areas of interest, they were all inspired by holistic approaches towards studies of man-land relations. In this holistic ideal is the ideal of interdisciplinarity, which was very explicitly expressed. The holistic ideal was identified as almost hegemonic. Based on an urge to understand landscape and landscape changes, the ideal draws mainly on the theoretical principles of landscape ecology (Zonneveld, 1995; Forman, 1996). ${ }^{15}$ Hence, the interviewees' lack of interest in cultural issues may not be due to a neglect of the importance of these issues, but can be interpreted within the interdisciplinary context where culture is something that other researchers are better at studying. Thereby, the interviewees' attitude towards social and cultural issues is that these can be included by cooperating with other researchers. The Danish research programmes on cultural landscapes enforced interdisciplinarity, this was seen as a positive outcome by the agri-rural research community. However, it is important to bear in mind that this holistic ideal is based on a positivist way of doing research and thereby have certain influences on the practice of doing research. Cultural issues are seen as what have been described by Crang (1998) as a 'residual variable' for all those things not accounted for in other fields.

\subsubsection{The empirical research ideal}

All of the interviewees expressed a preference for empirical research. Foremost, there was a tacit agreement that empirical material presents direct and 'true' answers to research questions. Here again the positivist way of doing research is clear: researchers should find out what is 'really

\footnotetext{
${ }^{14}$ By interdisciplinary we mean research that involves several unrelated academic disciplines in a way that forces them to cross subject boundaries to solve a common research goal (adapted from Tress et al., 2003).

${ }^{15}$ The Danish Society of Landscape Ecology - member of The International Association of Landscape Ecology (IALE) - is one of the few organised forums for agri-rural researchers. They arrange an annual conference on actual themes of rural planning.
} 
going on' in the landscape, and more empirical data and analysis is constantly needed to get wiser. This ideal can also be seen in their approach towards fieldwork. It is dominated by quantitative fieldwork based on survey methods; social information is regarded as stable and existing independently of the researcher. $\mathrm{He} / \mathrm{she}$ is more occupied with representativity and generalisations than with the establishment of context. Hence, fieldwork is '... based on the assumption that reality is present in appearance... and can therefore be directly apprehended through observation' and '... biased towards the evidence of the eye' (Smith, 2000, p. 267).

At the same time, both philosophy of science and conceptualisation were issues that did not engage the interviewees. Only one of them had clear reflections to where he/she saw him/herself in terms of philosophical approach - and this was within positivism. The others did not reflect upon its importance for their research. Likewise the interviewees preferred to 'look at the empirical facts' instead of discussing various conceptualisation and multiple realities. This lack of clear conceptualisations also meant that some issues were difficult to discuss, e.g., rural studies, due to uncertainties of how the conceptualisations were interpreted and used by the interviewees.

Moreover, the empirical ideal has little focus on philosophical and methodological implications of doing research because 'the world is out there', which means we just have to find the best ways to study it, to collect empirical material. This means that within the empirical discourse, it is legitimate not to reflect on the philosophical implications of one's research. As long as it is the empirical ideal together with the holistic ideal that are produced and reproduced in agri-rural research in Denmark, it may be difficult to promote an awareness of philosophical implications of such an approach.

\subsection{Institutional settings}

Understanding the institutional settings, i.e. institutional identities, structures, etc. are important for understanding the making of research in these institutions.

As mentioned, members of the agri-rural research community in Denmark work at three different universities and rural studies are conducted at eight different institutions. This could lead the reader to think that there is a flow of people from one institution to another. But this is not the case; as shown in the analysis, the majority of researchers remain within the institutions where they have received their training or at the institution where they got their first position. Most importantly, researchers remain at institutions within the research community. The lack of 'research flow' means that existing ways of thinking are reproduced without being questioned as there are few newcomers who can challenge the received wisdom. And these newcomers are usually young researchers, who may not want to challenge their supervisor or superior. As described earlier this is not something unique to the agri-rural research community but general for the Danish research society.

When researchers are trained at the very same institution where they end up being employed, it is almost inevitable they develop a strong institutional identity. ${ }^{16}$ Only confronted with one institution and way of doing research, academics from other institutions may appear as 'others' with strange attitudes and values. This 'othering' enforces the sense of institutional belonging.

The lack of research flow is obviously also related to the strong institutional belonging and identity of agri-rural researchers. One may ask what is the cause and effect-is the flow of researchers low because there they have a strong institutional identity and prefer to remain within one institution? Or do researchers get this strong institutional identity because of the limited mobility Danish academia? Our material does not allow us to answer this question, but it appears that the younger rural researchers are more open-minded towards change of institution and recently some changes have occurred.

\subsection{Funding mechanisms}

Another system that reproduces the way of thinking within academic institutions is funding mechanisms.

A major part of the last decade of interaction among researches in rural studies has been initiated and developed through a national focus on 'Cultural landscapes' from the national research councils. Approximately 96 million euros has been allocated to eight environmental and agricultural research programmes from 1992 to 1998 (Höll and Nilsson, 1999). By categorizing the individual research project into 11 categories, Höll and Nilsson show that interdisciplinarity in research programmes has become supplementary to monodisciplinarity where research is focused on one certain component of the environment-a tendency that has resulted in a necessity of interaction between researchers from different research fields. However, the numbers also show that research in the categories of 'social studies'17 and 'philosophy studies" 18 are very limited in relation to the other categories as, e.g., environment and agriculture. It appears that natural science has come to dominate the interdisciplinary research and there is little cooperation between people within and outside natural science.

\footnotetext{
${ }^{16}$ In Denmark, it is not very common to combine different subjects, not even for post-graduate studies. Geographers, for instance, can finish their master degree without having left the Institute of Geography at the University of Copenhagen. Likewise for agronomists, landscape architects, biologists, and architects. An exception is Roskilde University where cross-disciplinary studies are taught and the master degree has to involve two subjects. At Aalborg University the subject geography has recently been established starting with 13 students also having a cross-disciplinary approach.

${ }^{17}$ 'Social studies: Studies empirically investigating human attitudes and perception' (Höll and Nilsson, 1999, p. 18).

${ }^{18}$ 'Philosophy: Studies on how the concepts of 'nature' and 'culture' are used in different contexts of human activity, particularly in relevant policies' (Höll and Nilsson, 1999, p. 18).
} 
The university structure means that funding for research activities ${ }^{19}$ has to be secured through sources outside the university usually through national and/or European research funding programmes. At the research institutions, funding has to be raised for all costs. Also here research is mainly based on national and European research funding programmes. However the picture is getting more and more blurred; for instance universities do research for ministries and research institutions participate in teaching at the universities.

Many funding opportunities are dependent upon research having direct policy relevance and further that such research are often met by the demand of predicted outcomes (Adriansen and Madsen, 2004). This means that some issues are neglected already in the initial project proposal if they appear unpredictable. For example, as argued by Morris and Evans: 'It is understandable that [agricultural] work has not been more culturally sensitive, because much of it has been delivered within a 'policy evaluation' mould. The monitoring brief demanded by government agencies leads inevitably to questionnaire-type approaches...' (Morris and Evans, 1999, p. 354). The historian Michael Wagner has made a study of the Danish funding system and found that this is dominated by natural scientists and engineers who favours natural science methods, predicted outcomes and applied research. ${ }^{20} \mathrm{He}$ explains: 'In order to get money, it is necessary to legitimise the direct application of one's research purpose. It appears that we as researchers need to think in advance how our research will be of use, what good it will provide, before we can allow ourselves to write an application' (Øllgaard, 2005, p. 21). Hence, the funding system is biased towards natural science and researchers know this and impose constraints on themselves when they apply for research funding.

\section{Comparing 'fashions'}

In the following we relate 'fashions' in Danish and British agri-rural research. This is done without having a comparative scope in mind but instead as a way of "playing against' the dominant Anglo-American geography.

\subsection{The cultural turn in British rural research}

In recent years, geography in the UK has experienced a 'cultural turn' (Barnett, 1998; Philo, 2000). This has been more pronounced within some geographical sub-disciplines than others. Rural geographers, for example, have embraced the cultural turn, while agricultural geography represents an 'awkward case' with respect to the interest in cultural issues (Morris and Evans, 2004, p. 96). Based on a

\footnotetext{
${ }^{19}$ Funding for research activities means funding covering research costs, wages of employees at the universities are secured through the basic university funding.

${ }^{20}$ For an in-depth discussion of the problems in relation to demanding predictable outcomes and public relevance, please refer to Demeritt (2000) who has analysed the 'new social contract for science'.
}

conceptual fascination with difference and a methodological fascination with ethnography, the cultural turn has brought new perspectives to and re-emphasized existing themes within the rural context (Cloke, 1997). The construction of knowledge by academics is one of the 'new' research issues. The premises for knowledge production were highlighted when Murdoch and Pratt (1993) called for studies of the 'post-rural' in the notion that actors with 'power' impose 'their' rurality on others. Following this call, many studies have shown that the rural is a constructed and contestable concept (e.g. Pratt, 1996; Cloke and Little, 1997; Frouws, 1998; Richardson, 2000). Different methods for studying this variety of ruralities have been put forward (e.g. discourse analysis, qualitative interviews, participatory observations) and have led to a range of interesting perspectives on both the rural and the study of the rural. The idea of the rural has become seen as a socially constructed and complex discursive category. This implies that actions are understood as socially embedded, for instance farmer behaviour should be interpreted within the local farming culture and cannot be modelled on basis of, e.g., economic variables.

It should be noted that not only are new issues such as territoriality and belonging, otherness, identity of rural dwellers, and constructions of rurality (see, e.g., Cloke and Little, 1997; Halfacree, 1995; Morley, 2001; Phillips et al., 2001; Saugeres, 2002) brought to attention, but also certain methods are advocated. There is a focus on ethnographic methods including qualitative interviews and interactions with the field - the research process is re-thought in order not to reproduce the 'them' and 'us'. Further, discourse analysis and network theory have gained influence. Also the relevance of new materials such as the interpretation of film, music, and poetry has been put forward. Researchers emphasising the cultural turn do not work in a philosophical vacuum where everything goes. The new issues, methods, and materials cannot just be mixed with 'conventional' rural studies. Identity, for instance, is not just another variable to be added to a model or invoked in a GIS. This detaches culturally inspired rural studies from natural-science based studies both in issues of relevance and in approach. And as noted by Cloke: 'Such accounts, though often marketed as 'theory-free', are implicitly positivistic, and far from being 'back there' somewhere at an historic point of the journey' (1997, p. 369). Instead culturally inspired rural studies can be characterised by using culture as the starting point for understanding rurality in its various forms.

\subsection{Why Danish rural research did not turn cultural}

While British rural studies have been very inspired by the cultural turn, this seems to have bypassed Danish rural studies. During the interviews, it was very clear that cultural issues where regarded a variable that can be described and added to existing knowledge of landscape and landscape changes. For example the values and 
attitudes of actors (e.g. landowners, forest owners) creating landscape changes are regarded as an additional topic of research to complete the whole picture of landscape change and planning intervention. In practice, farmers' values are for instance combined with other factors like, e.g., soil quality, farm structure in statistical analyses in order to explain the given landscape changes. The methodological and philosophical implications of such an approach are not seen as problematic due to the ideal's position within a positivist research setting.

As mentioned, the empirical ideal dominate Danish agrirural research. A function of this ideal is that it is legitimate not to reflect on the philosophical implications of one's research. As long as the empirical ideal together with the holistic ideal are produced and reproduced in agri-rural research in Denmark, it may be difficult to promote an awareness of cultural issues within the agri-rural research community.

Another explanation may be that there is no 'critical masses' of researchers, which can ensure that a wide variety of new issues are brought to the attention of the research community. With reference to human geography in general Simonsen (2004, p. 527) has pointed out that the cultural turn, which has taken place in Danish human geography, never has involved an opposition between the material and the cultural and she discusses if this is due to the fact that the critical geography community in Denmark is too small to 'afford the luxury of division'. However, it is difficult to assess the importance of the size of a given community for the development of certain ideas, and other explanations are needed too.

Finally, the limited influence on Danish agri-rural research from the cultural turn also relates to networking and the practices of research communities. ${ }^{21}$ There are examples of Danish researchers outside the community who have more or less explicitly embraced the issues and methodologies of the cultural turn in relation to rural research, e.g., Alrøe and Kristensen (2002), Oldrup (1999), Olwig (2002), Svendsen (2004), Pedersen and Kjærgård (2004). The problem, however, is that there is very little interaction between the agri-rural research community and some of these other communities - despite the explicit emphasis on interdisciplinarity within the agri-rural community. We find that the agri-rural research community is a dominant one in geographical rural research but as the above indicates it is not exhaustive.

\subsection{Lessons that can be learned from Danish rural research}

Each philosophical tradition and theoretical approach have their own strengths. We contend that it is valuable to

\footnotetext{
${ }^{21}$ It should be noted that by limiting our definition of the cultural turn to only post-modern and social constructionist approaches can blind us for some research contributions. However, we find this definition the most fertile way of analysing the degree of cultural turn within Danish agrirural research community and refer to Simonsen $(2003$, 2004) for a discussion of the cultural turn in Danish geography in general.
}

continue theoretically diverse research so that different attention can be given to the equally important affects of the material and the social. We find two trends in the Danish rural geography that could be brought into British rural geography; namely relating research in developed and developing countries to each other and the focus on the physical world and its development.

While British rural studies in the last decade has been enriched by the cultural turn, the empirical focus seems to be limited to certain cultures - it is difficult to find studies concerned with 'Third World' countries. There appears to be a division between 'developed' and 'developing' countries. We find this division is an unnecessary boundary precluding us from inspiration and insights gained in 'the other' world. Instead of studying either developed or developing countries, a more fertile approach is to focus on the issues of interest. We do not advocate comparative studies, as these often reproduce the boundaries; instead we find that the differences in answers can be of inspiration for asking new questions within the respective areas of research (Adriansen and Madsen, 2004).

Although Danish agri-rural researchers did not combine research from different worlds, i.e. from developed and developing countries, they still thought that rural studies was a subject that transcends this boundary. Moreover, a decade ago it was quite common for Danish rural researchers to conduct research in both developed and developing countries. We find that this a fertile approach, one which researchers in the Anglo-American world can learn from. The need to speak 'across worlds' has already been acknowledged by some researchers in the AngloAmerican world. This was seen at the Royal Geographical Society's annual conference in London 2005, where a session was devoted to research of rural youth in both developed and developing countries.

The other lesson that can be learned from Danish rural studies is the focus on the physical world and its development, e.g., understanding of landscape management and development in an agri-political context. In the process of the 'cultural turn period' in British rural geography, we have found that the physical/material aspects of life in rural areas and the use of rural space often have been omitted. We would argue for a (re-)turn to these physical aspects, but to do it within the light of culturally inspired studies. Hence, the aim is to provide an understanding of rural people and their land use by considering them in a broader context of the social and cultural embeddedness of their actions.

\section{Conclusion}

This paper has called attention to the construction of scientific knowledge in research communities. It relies on the idea presented by Lorimer and Spedding (2002a, p. 227): 'As we turn our attention to the making of knowledge, so too must we locate ourselves in the 
spaces in which these events unfold'. Hence, we want to point to the importance of studying the making of scientific knowledge in the same way as other types of knowledge.

The Danish agri-rural research community was used as the empirical basis for studying the making of scientific knowledge. By looking not only at the institutions where agri-rural research is produced but also at the research community itself, attention was drawn to the space for knowledge circulation and reproduction. Hence, it is based on the idea that the development of research discourses and fields of legitimate research are enriched by locating the researchers, their practices, theories and conceptualisations in their spatial contexts, whether these are material or metaphorical (Livingstone, 2000).

The agri-rural community in Denmark is dominant in geographical rural research although not exhaustive. The interviewees had very similar perceptions of the unarticulated boundaries of the research field and of the way the rural is studied. This constitutes what we have named the fields of legitimate research. This field is characterised by two strong and interwoven research ideals based on empirical and holistic ideals towards research combined with an institutional setting within a natural science environment. Within the community there has been an emphasis on understanding and describing landscape and landscape changes. Agriculture is perceived as the determining factor for landscape change and the research has not moved 'beyond the farm gate' to use Whatmore's (2000) terminology. There is an acknowledgment of other influential factors than agriculture but they are often considered less tangible and thereby less 'scientific' and seldom included in the analysis. The rural is not considered a socially constructed place but instead a physical place where cultural issues are seen as a residual variable for all those things not accounted for in other fields. Aspects such as post-modern and post-structural understandings of society-space, nature-society, and self-other are not studied by the researchers in this community.

This paper has shown that 'fashions' in Danish rural research differ from 'fashions' in the UK. Danish rural researchers are not engaged with the cultural turn that has marked British rural geography for more than a decade now. As British rural studies move within and beyond the cultural turn to reengage with the materiality and physically of daily lives, the approaches developed within Danish agri-rural research can be of inspiration. In this way, we have given insights into the research world of those doing geography outside British rural geography. It is a report from the periphery of the dominating AngloAmerican geographical writing space. We find it important that national academic discourses learn from each other and in a way the analysis can be seen as a 'country report' of the agri-rural community and its research in Denmark. However, as other 'maps' of intellectual landscapes, a country report is a social construction, which is situated, partial and only a snapshot of reality.

\section{Acknowledgements}

This study was financed by grants from the Danish Social Science Research Council and the Danish Agricultural and Veterinary Research Council. It is based on interviews with our colleagues and we are indebted to them for having shared their time and knowledge with us. Interviewing colleagues is not an easy task neither for the interviewer nor for the interviewee. However, they have all willingly answered our often 'strange' questions and we thank them for making it possible. They were promised anonymity, so their names will not be mentioned. We are further indebted to many people for having discussed this paper with us. In particular Carol Morris, Henry Buller and Gunnar L. H. Svendsen should be thanked for their valuable comments. Finally, we also wish to thank three referees of this journal for their helpful and constructive suggestions. All usual disclaimers apply.

\section{References}

Adriansen, H., Madsen, L.M., 2004. Constructing multiple ruralities: practices and values of rural dwellers. In: Holloway, L., Kneafsey, M. (Eds.), Geographies of Rural Cultures and Societies. Ashgate, London, pp. 79-99.

Alrøe, H.F., Kristensen, E.S., 2002. Towards a systemic research methodology in agriculture: Rethinking the role of values in science. Agriculture and Human Values 19 (1), 3-23.

Barnett, C., 1998. The cultural worm turns: fashion or progress in human geography? Antipode 30, 379-394.

Bensel, R., 2003. The tension between American political development as a research community and as a disciplinary subfield. Studies in American Political Development 17 (1), 103-106.

Bradshaw, M., 2001. Contracts and member checks in qualitative research in human geography: reason for caution? Area 33 (2), 202-211.

Browne, K., 2003. Negotiations and fieldworkings: Friendship and feminist research. ACME: An International. E-Journal for Critical Geographies 2 (2), 132-146.

Cloke, P., 1997. Editorial, Country backwater to virtual village? Rural studies and 'the cultural turn'. Journal of Rural Studies 13 (4), $367-375$.

Cloke, P., 2000. Rural geography. In: Johnston, R., Gregory, D., Pratt, G., Watts, M. (Eds.), The Dictionary of Human Geography, fourth ed. Blackwell Publishers, Oxford, pp. 719-720.

Cloke, P., Little, J., 1997. Contested countryside cultures, otherness, marginalisation and rurality. Routledge, London, New York.

Crang, M., 1998. Cultural Geography. Routledge, London.

Demeritt, D., 1996. Social theory and the reconstruction of science and geography. Transactions of the Institute of British Geographers (NS) 21 (3), 484-503.

Demeritt, D., 2000. The new social contract for science: accountability, relevance, and value in US and UK science and research policy. Antipode 32 (3), 308-329.

Ehn, B., Löfgren, O., 2004. Hur bliver man klok på universitetet? Samfundslitteratur, Lund.

Elwood, S.A., Martin, D.G., 2000. Placing interviews: location and scales of power in qualitative research. Professional Geographer 52 (4), 649-657.

Forman, R.T.T., 1996. Land Mosaics: The ecology of Landscape and Regions. Cambridge University Press, Cambridge.

Frouws, J., 1998. The contested redefinition of the countryside. An analysis of rural discourses in the Netherlands. Sociologia Ruralis 38 (1), 54-68. 
Halfacree, K., 1995. Talking about rurality: social representation of the rural as expressed by residents of six English parishes. Journal of Rural Studies 11 (1), 1995.

Höll, A., Nilsson, K., 1999. Cultural landscape as subject to national research programmes in Denmark. Landscape and Urban Planning 46 (1), 15-27.

Johnston, R., 2003. Geography: a different sort of discipline? Transactions of the Institute of British Geographers (NS) 28 (2), 133-141.

Kitchin, R., Fuller, D., 2003. Making the 'black box' transparent: publishing and presenting geographic knowledge. Area 35 (3), 313-315.

Knorr-Cetina, K., 1981. The Manufacture of Knowledge: An Essay on the Constructivist and Contextual Nature of Science. Pergamon Press, Oxford.

Kuhn, T., 1962. The Structure of Scientific Revolutions. University of Chicago Press, Chicago.

Kvale, S., 1996. InterViews. An Introduction to Qualitative Research Interviewing. Sage, London.

Latour, B., Woolgar, S., 1986. Laboratory Life, the Construction of Scientific Facts, second ed. Princeton University Press, Princeton.

Liepins, R., 2000a. New energies for an old idea: reworking approaches to 'community' in contemporary studies. Journal of Rural Studies 16 (1), 23-35.

Liepins, R., 2000b. Exploring rurality through 'community': discourses, practices and spaces shaping Australian and New Zealand rural 'communities'. Journal of Rural Studies 16 (3), 325-341.

Livingstone, D.N., 2000. Putting geography in its place. Australian Geographical Studies 38 (1), 1-9.

Lorimer, H., Spedding, N., 2002a. Editorial, putting philosophies of geography into practice. Area 34 (3), 227-228.

Lorimer, H., Spedding, N., 2002b. Excavating geography's hidden spaces. Area 34 (3), 295-302.

Madsen, L.M., Adriansen, H.K., 2004. Understanding the use of rural space: the need for multi-methods. Journal of Rural Studies, forthcoming.

Morley, D., 2001. Belonging, place, space and identity in a mediated world. European Journal of Cultural Studies 4 (4), 425-448.

Morris, C., Evans, N., 1999. Research on the geography of agricultural change: redundant or revitalised. Area 31 (4), 349-358.

Morris, C., Evans, N., 2004. Agricultural turns, geographical turns: retrospect and prospect. Journal of Rural Studies 20 (1), 95-112.

Murdoch, J., Pratt, A.C., 1993. Rural studies: modernism, postmodernism and the 'post-rural'. Journal of Rural Studies 9 (4), 411-427.

Oldrup, H., 1999. Women working off the farm: reconstructing gender identity in Danish agriculture. Sociologia Ruralis 39 (3), 343-358.

Olwig, K., 2002. Landscape nature and the body politic, from Britain's renaissance to America's New World. The University of Wisconsin press, Madison.
Pedersen, K.B., Kjærgård, B., 2004. Do we have room for shining eyes and cows as comrades ? Gender perspectives on organic farming in Denmark. Sociologia Ruralis 44 (4), 373-394.

Phillips, M., Fish, R., Agg, J., 2001. Putting together ruralities: towards a symbolic analysis of rurality in the British mass media. Journal of Rural Studies 17 (1), 1-27.

Philo, C., 2000. More words, more worlds: Reflections on the cultural turn in human geography. In: Cook, I., Crouch, D., Naylor, S., Ryan, J. (Eds.), Cultural Turns/Geographical Turns. Longman, London, pp. 26-53.

Pratt, A., 1996. Discourses of rurality: loose talk or social struggle? Journal of Rural Studies 12 (1), 69-78.

Richardson, T., 2000. Discourses of rurality in EU spatial policy: the European spatial development perspective. Sociologia Ruralis 40 (1), 53-71.

Saugeres, L., 2002. The cultural representation of the farming landscape: masculinity, power and nature. Journal of Rural Studies 18 (4), 373-384.

Sidaway, J., 1997. The production of British geography. Transactions of the Institute of British Geographers (NS) 22 (4), 488-504.

Sidaway, J., 2000. Recontextualising positionality: geographical research and academic fields of power. Antipode 32 (3), 260-270.

Simandan, D., 2002. On what it takes to be a good geographer. Area 34 (3), 284-293.

Simonsen, K., 2003. On being 'in-between': social and cultural geography in Denmark. Social \& Cultural Geography 4 (2), 255-268.

Simonsen, K., 2004. Differential spaces of critical geography. Geoforum $35,525-528$.

Smith, S.J., 2000. Fieldwork. In: Johnston, R., Gregory, D., Pratt, G., Watts, M. (Eds.), The Dictionary of Human Geography, fourth ed. Blackwell, Oxford, p. 267.

Ståhle, B., 2004. En forskerstab i forandring, forskerpersonale og forskerrekruttering på danske universiteter 2001-2003. UNI C Statistik og Analyse.

Svendsen, G.L.H., 2004. The right to development: construction of a nonagriculturalist discourse of rurality in Denmark. Journal of Rural Studies 20 (1), 79-94.

Tress, B., Tress, G., van der Valk, A., Fry, G., 2003. Interdisciplinary and transdisciplinary landscape studies: potential and limitations. DELTA series 2, Alterra Green World Research. Landscape Centre, Wageningen.

Wenneberg, S.B., 2002. Socialkonstruktivisme, positioner, problemer og perspektiver. Samfundslitteratur, Frederiksberg.

Whatmore, S., 2000. Agricultural geography. In: Johnston, R., Gregory, D., Pratt, G., Watts, M. (Eds.), The Dictionary of Human geography, fourth ed. Blackwell, Oxford, pp. 10-13.

Zonneveld, I.S., 1995. Land Ecology. SPB Academic Publishing, Amsterdam.

Øllgaard, J., 2005. Ingeniørernes høje selvfølelse.... Forskerforum 183, $20-21$. 